\title{
The Process of Approaching and Implementing Experiential Learning for Teaching Maths to Junior Secondary School Students in Viet Nam
}

\author{
Nguyen Huu Tuyen* \\ Bacninh Teacher Training College, Vietnam \\ *Corresponding author: nguyenhuutuyen.bacninh@moet.edu.vn
}

\begin{abstract}
Vietnam's current general education curriculum is designed in a content-oriented manner and there is a lack of capability-orientation for students. With the requirement of human resource training for the country's industrialization and modernization, the Vietnamese Communist Party Central Committee promulgated Resolution No. 29-NQ/TW dated 4 November 2013 with the basic orientation for the fundamental and comprehensive reform of education and training in Vietnam. One of its major breakthroughs is to renovate the teaching and learning methods in learners' capacity development-oriented manner. Teaching mathematics to junior secondary school students through experiential activities is of considerable interest to a large number of Vietnamese authors nowadays. It is not only appropriate for the psychological characteristics of the junior secondary school students, who gradually shift from the learning method based on visual model and conceptual description at the elementary level to the learning approach based on conceptual definitions and logical reasoning; but it also meets the orientation of mathematical education in Vietnam's new General Education Curriculum. In order to reach these goals, it is required of the teachers to have appropriate and effective ways in the organization of experiential activities to meet the requirements of the educational reform. As a matter of fact, the proposals for implementing experiential learning in Maths classes for junior secondary school students is not yet of great concern. This article discusses the approach of Vietnamese education in recent years in order to catch up with the new General Education Curriculum, which is expected to be nationwide applied in 2019. A number of steps for organizing experiential activities for Mathematics learners are also mentioned in the paper.
\end{abstract}

Keywords: experiential learning, the organization of experiential activities, new general education curriculum, mathematics teaching, junior secondary school students

Cite This Article: Nguyen Huu Tuyen, "The Process of Approaching and Implementing Experiential Learning for Teaching Maths to Junior Secondary School Students in Viet Nam.” American Journal of Educational Research, vol. 6, no. 6 (2018): 877-882. doi: 10.12691/education-6-6-42.

\section{Introduction}

Vietnam's current General Education Curriculum has a number of shortcomings compared to that of developed countries. It is a content-oriented Curriculum which focuses on imparting the knowledge to learners.

With a view to developing students' necessary capabilities for the national industrialization, modernization and international integration, the new General Education Curriculum, which combines knowledge and moral education with career orientation, is designed to create radical and comprehensive changes in both quality and efficiency so that students can achieve a comprehensive development in their both personal quality and capability, as well as a harmonious development in morality, intellect, physique, and aesthetics, and help bring out the best in each student. [1].

Education through experiential learning has become an orthodox educational ideology which is associated with psychologists and educators such as John Dewey, Kurt Lewin, Jean Piaget, lev Vygotsky, David Kolb, William James, Carl Jung, Paulo Freire, Carl Rogers... and now the idea of "learning through experience" or "experiential learning" is still one of typical educational trends and has become part of the National Education Program in many countries throughout the world such as Korea, Japan, China, Hong Kong, Singapore, Finland ... [2,5].

However, in Vietnam, the term "education through experience" appeared in the draft of the New General Education Curriculum which was developed four years ago and was officially announced in July 2017. The New General Education Curriculum including the education of school subjects (both compulsory and optional), careeroriented activities and compulsory education of localities will be implemented nationwide in 2019.

During the process of designing the New General Education Curriculum, the Vietnam's Ministry of Education and Training (MOET) organized many training courses on learners' quality ad capacity development oriented teaching in which experiential learning were 
implemented in a number of schools in order to help teachers and students get acquainted with the new program. However, there has not been much study or research on teachers' method of organizing experiential activities in career-oriented education as well as in Maths classes at junior secondary schools.

\section{Vietnam's Approach during the Process of Building the New General Education Curriculum on Experiential Learning}

On November 1st, 2012, MOET issued Decision No. 4763/QĐ-BGDĐT approving project "Building a school model with the synchronous innovation in teaching methods and assessment in the period 2012-2015 ".

On May, 27 ${ }^{\text {th }}, 2013$, the MOET issued the Official Letter No. 3535/BGDĐT-GDTrH guiding the application of method "hand-to-knead powder". On June 25 2 , 2013, MOET made the Guideline No. 791/HD-BGDĐT on piloting the development of the new General Education Program. Under the guidance above, junior secondary schools are allowed to be flexible in developing teaching plans, selecting suitable teaching contents for each level of students, creating favorable learning and teaching conditions and selecting appropriate teaching venue for all the school subjects.

Many schools and localities have been creative and successful in implementing new teaching methods in the orientation of organizing experiential activities for students. Based on the success of pilot schools during the implementation process in recent years, the trend towards experiential learning has been expanded throughout the country, which can be seen through the guiding documents for the implementation of tasks in each school year for junior secondary schools.

In order to achieve greater success in experiential learning for different subjects, the MOET continued to issue Official Letter No. 5555/BGDĐT-GDTrH dated 08/10/2014 with further guidance on some key tasks such as the requirements for building thematic teaching plans in each subject, thematic integration and interdisciplinary subjects so that those teaching plans of a single subject or interdisciplinary subjects are consistent with the target of the General Education Curriculum, and appropriate for the real conditions of the school, locality as well as students' academic capabilities.

In the construction of thematic teaching plans, teachers are permitted to select the content of teaching for their subjects suitable for the teaching method and the reality of the school rather than following the sections in the textbook. Based on the requirements for the students' knowledge, skills and attitudes for the whole course in general ad for each section in particular, experiential activities will be organized in the combination with learner-centered and active teaching methods so that the desired qualities and skills can be built and improved for each student after each section.

In the compilation of questions or assignments for students, it is essential that the four major categories of educational objectives (Knowledge, Comprehension,
Application and Higher application) should be identified and described, and can be used to examine and evaluate students' competence and qualities. It is advisable that the pedagogical process can be organized in the form of inclass and out-of-class activities so that students not only learn from teachers' classroom techniques but they also pick up from experiential activities outside classroom.

Students are given a variety of tasks such as completing the assignments, discussing and reporting the outcomes, self-evaluating and evaluating their peer's performance. The assessment of teaching process has been emphasized by MOET on three core subjects: Firstly, the teaching plans and teaching materials are put into four categories based on the four factors: the appropriateness of the learning activities with the objectives, contents and teaching method; the clarity level of objectives, contents, organization and required outcome that each student should reach for each learning task; the appropriateness of teaching devices and learning materials used during students' learning activities; the suitability of testing and assessment during the course.

Secondly, the organization of students' learning activities is divided into different levels which are based on the four factors: the liveliness, attractiveness towards students from the organizational methods, the teacher's capacity in monitoring, observing and detecting students' difficulties; the relevance and effectiveness of the measures which are used to support and encourage students to cooperate, help each other when performing their tasks; the effectiveness of teachers in synthesizing, analyzing, evaluating students' results and discussion process.

Thirdly, students' activities are divided into degrees of four factors: the whole class's ability to receive and perform the tasks; the level of students' enthusiasm, activeness, creativity and cooperation in the implementation; the level of students' participation in presenting, and discussing the performance of learning tasks; the degree of correctness, accuracy, relevance of the students' results for each task [3].

Nguyen Tat Thanh Junior and Senior High School in Hanoi was selected as one of the pilot units in the spirit of Official letter 791/BGDĐT-GDTrH according to the approved scheme in March 2013: "Building the experiential school Nguyen Tat Thanh according to the students' capability development model". The school has developed a curriculum that includes mathematics at the junior high school level with a view to increasing its practicality, developing teaching plans and teaching organization towards experiential learning in various aspects. Along with the design of experiential activities in a number of subjects, the school has promoted extra educational activities in moral education, life value, life skills, social understanding, law practice, etc.

With the establishment of many clubs such as Arts, Sports, Event organization, Music, English, Green Environment, Reporters with a view to maximizing individual strengths, building and developing student's personalities.

Hand-made kneading method has been practiced by most junior high schools especially in the natural sciences. Many lecture designs have the orientation of organizing experiential learning activities. 
Since 2012, MOET has promoted the playgrounds and intellectual competitions for teachers and students at junior high school level. As the result, the well-designed lesson plans combining with interdisciplinary themes and integrated teaching have attained good achievement. In most subjects especially Mathematics, many lessons are designed in the approach of organizing experiential activities in which the content is closely attached to reality.

On November 2, 2012, MOET promulgated the Regulation on Science and Technology Examination for junior and senior secondary school students, attached with Circular No. 38/2012/TT-BGDĐT with the aim at "encouraging senior secondary school students to study and apply the knowledge of school subjects to solve practical problems; contributing to the reform of organizing teaching styles; making changes in the forms and methods to evaluate learning outcomes; developing students' capacity and personalities; promoting teachers to improve their professional skills ad improving the quality of teaching in secondary schools; promoting the organization of educational activities through experience in accordance with students' capability and personalities' development orientation; organizing the competitions for students in science, technology, engineering and mathematics (STEM) in general education under the Prime Minister's Directive No. 16/CT-TTg dated May 4, Fourth Industrial Revolution ". There are 22 areas for students; in which the field of mathematics includes Algebra, Analysis, Discrete, Game and Graph Theory, Geometry and Topology, Numerical Theory, Probability and Statistics, ...

Since the year 2012, the contest has been expanded, developed and attracted students from 64 provinces nationwide with thousands of projects each year. Hundreds of excellent products have joined the annual national competitions and been selected to attend the international events in the United States and achieve positive results. In this form of teaching and learning, students actually experience practical activities under the guidance of teachers and scientists.

Students have opportunities to apply their knowledge and skills learnt from many subjects, in which mathematics is present in many projects. In the process of experiencing, the students continuously perform the 4-step cycle of D. Kolb; discrete experiences manifested immediately; reflection of students and the support of the scientist and teacher are constantly implemented and especially the students bravely test their judgments or decisions. The original product is tested and new experiences are drawn, with judgments get adjusted,...

\section{The Notion of Organizing Experiential Activities for Students in Teaching Mathematics at Junior High School Level}

- Organizing students' study through experiential activities:

During the organization of experiential activities, students should be put in the state of experiencing things with a variety of senses ranging from sensation to perception and individual emotion. Later on, students must be granted the chance to present and express a wide variety of their life experiences and knowledge and they should also be given the opportunity to show their values to others such as educational specialists or someone who is more knowledgeable in their own point of views.

According to Finger's viewpoint in the HewlettPackard Bulletin, it is of great importance that students play the roles of scientific researchers whose primary purpose is to build knowledge in an objective and natural way. What students achieve comes from their own experience and their improvement can be seen as their adaptation to the real environment.

In Coleman's opinion, the process of experiential learning has four steps as the following:

+ Step 1: Students participate in an activity in a specific circumstance or in a special context where the effects of this activity can be seen immediately.

+ Step 2: Students try their best to understand the nature of the effects from the past situation by guessing what has happened or making predictions about what will happen and how things will go in similar situations.

+ Step 3: Students are supposed to understand the most common major principles which lead to the same result in such situations. This requires students' capability in establishing causal relationships, making a connection between the action and the outcome they have had in the past situation; and students are required to make inference based on the various changes in their actions so that they can make logical prediction or point out the outcome which is obtained from each change.

+ Step 4: Finally, students have to generalize the principle obtained in the past causal relationship as the basis for dealing with new or slightly different situations. Students need to be able to make prediction about its causal relationship in order to institutionalize the knowledge they have acquired [4].

To sum up, the organization of experiential activities for student in Mathematics is the process of creating experiential environment, designing experiential activities, assigning tasks to students, guiding and evaluating students' outcomes through their experiential learning.

\section{The Characteristics of Mathematics Teaching Program for Vietnamese Junior Secondary School Students}

In the new General Education Curriculum, the content of lower secondary education includes various subjects, compulsory educational activities and locality education such as Literature; Mathematics; Foreign Language 1; Civic education; History and Geography; Natural Sciences; Technology; Informatics and Physical education; out-of-class educational activities and Career Oriented education. The subjects like Technology, Informatics, Physical Education are designed as units while the ones like career orientation and out-of-class educational activities are designed as themes. In order to organize experiential activities for each subject, students choose the section or the topic which suits their aspirations and the school's real condition. 
Career-oriented education is integrated in both compulsory subjects and educational activities. For example, in grade 8 and 9, many subjects like Technology, Computer Science, Natural Sciences, Arts, Citizenship, Career Orientation, and Local Education have the teaching content related to career orientation. Mathematics education helps to build up and develop students' qualities and skills in general as well as mathematic skills and competence with such core elements as the capability in mathematical thinking, arguing, modeling, math problem solving, math communicating, using tools and means to learn math; develop critical knowledge and skills and provide opportunities for students to experience, apply mathematics to real life. Mathematical education creates a connection between mathematical ideas, between mathematics and other disciplines, and between mathematics and real life [1].

Mathematics is the core subject as it is in many subjects such as Mathematics, Physics, Chemistry, Biology, Technology, Informatics, Experimental Activities, Natural Science, etc. are in mathematics..

\section{- Characteristics:}

Math characteristics are outlined in the syllabus of the syllabus (Published on January 19, 2018 by MOET): Mathematics has more and more applications in life, basic mathematical knowledge and skills. It helps people solve problems in real life systematically and precisely, contributing to the development of the society. Mathematics at school contributes to the formation and development of students' quality and personality; developing key knowledge and skills and providing opportunities for students to experience, apply mathematics to real life; Creating connections between mathematical ideas, mathematics and reality, mathematics and other subjects, especially with subjects in the STEM field.

Mathematics content is often abstract, generalized. Therefore, in order to understand and learn Maths well, the school Maths program needs to ensure a balance between "learning" knowledge and "applying" knowledge to problem-solving. In the process of learning and applying mathematics, students always have the opportunity to use modern technology, teaching equipment, especially computers and calculators to support their presenting, exploring knowledge, solving math problems.

In the new General Education Curriculum, the content of mathematics is divided into two phases:

+ Elementary Education Phase: Math is compulsory in elementary and junior high school, helping students to systematically grasp the concepts, principles and mathematical rules needed for everyone, which is the basis for further study at higher level of study or can be used in daily life.

The mathematics phase of basic education combines the linear structure with the "concentric spiral" structure (concentric, extended and gradually advanced), revolving around and integrating three disciplines: Algebra; Geometry and Measurement; Statistics and Probability.

+ Career Orientation Education (Secondary School): Math is a compulsory subject at secondary school. Mathematics at this stage also incorporates a linear structure with a "concentric spiral" structure, revolving around and integrating three circuits of knowledge: number and algebra, geometry and measurement, statistics and probability.

\section{- Target:}

The goal of Mathematics at the junior high school level is to help students achieve the following key objectives:

a) Contributing to the formation and development of mathematical competence with the requirements: being able to argue reasonably when solving a problem, knowing that the mathematical proposition is not too complicated; being able to use mathematical models (mathematical formulas, algebraic equations, representations, etc.) to describe situations posed in practical mathematical problems; using mathematical language in combination with common language to express mathematical content as well as show evidence, manner and result of argument; describe the idea and use of tools, means of learning math to perform a learning task or to express the arguments, mathematical proof.

b) Having basic mathematical knowledge and skills in:

- Number and Algebra: Number system (from natural number to real number); calculating and using calculation tools; language and algebraic symbols; Algebraic expressions, equations, systems of equations, inequalities; Using the functional language to describe (model) certain processes and phenomena in the real world.

- Statistics and Probability: being able to perfect the ability to collect, process and display statistical data; initially explore the statistical data analysis tools; recognize simple statistical rules in practice; use statistics to understand the basic concepts of probability and apply probability into statistics; having the ability to recognize the meaning of probability in practice.

- Geometry and Measurement: geometrical language, symbols and description of objects in the surrounding world in geometric language; drawing (graphic), rendering, calculating geometric elements; the properties of the plane geometry (at the level of logical reasoning) and of the spatial object (at the visual level); develop imaginative space; Use geometry to solve practical problems.

c) Forming and developing the common and specific qualities that mathematics brings: discipline, persistence, initiative, flexibility, independence, creativity, cooperation; excitement and confidence in learning mathematics.

d) Contributing to the students' understanding as a basis for the orientation of post-secondary education.

\section{Steps for Organizing an Experiential Activity in Teaching Mathematics at Junior Secondary School Level}

With the psychological characteristics of the junior high school students, the characteristics and goals of the Secondary Mathematics Program, we introduce the steps of organizing an experiential activity for teaching mathematics to junior high school students as follows:

Step 1. The teacher selects content, venues, and conditions for the organization of the activity: Not all content can be effectively organized as experiential activities for teaching mathematics to junior high school students. 
The selection of content should be based on the lesson objectives; suitable with the psychological characteristics of the students' age and conditions of facilities and practices to generate learners' excitement, increase the ability to explore knowledge; this is linked to the ability to mobilize the experience of students. The selected content of the activity must help students to access or participate directly in the activity.

Step 2. The teacher designs the experiential activity for students (in a four-step process):

- Selecting the ways to bring learners into the experience, initiate and mobilize experiences.

- Observing, pondering to filter the core experiences related to the signs of judgment, or the sign that leads to students' decision in solving the learning situation.

- making judgment and decision to form new concepts.

- Implementing and applying to the new situation.

Step 3. The teacher gets students to participate in the experiential activity:

- Creating an experiential environment: Experienced environment helps students to have a sense of wishes and willing to participate in the activity, which is the motivation for students to join the activity.

- Organizing the activities for students according to the following design:

+ Suggestions for assigning tasks: Teachers can directly assign tasks to individual students or gradually train groups to be more active.

+ Organizing the implementation of tasks: The teacher observes to encourage all students to actively participate in the activities, taking direct measures or sending friends to help other students in need.

+ Organizing students' reports: Groups and individuals report their products as the teacher requires.

Step 4. Evaluating the activity: Making an assessment and giving reward (if it is possible).

Step 5. Teachers share experiences, concluding core issues; making suggestions to reflect on the process and results of the activity; applying to new situations and put into practice: the teacher summarizes accurate results to help students achieve the lesson's objectives.

- Steps for Organizing an experiential activity in Mathematics Teaching at junior Secondary Schools: The steps are summarized in the following diagram:

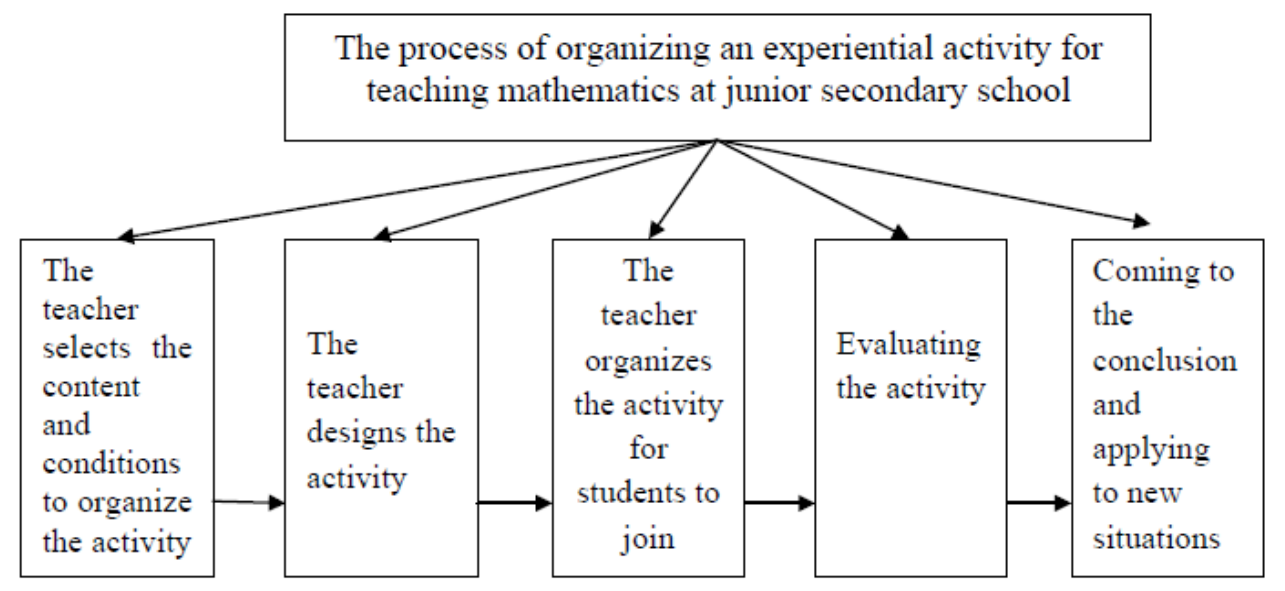

The following is a detailed description of the teacher's and students' activities:

\begin{tabular}{|c|c|c|}
\hline Steps & Teacher's activities & $\begin{array}{r}\text { Students' activities } \\
\end{array}$ \\
\hline 1 & $\begin{array}{l}\text { Select contents and conditions to organize the experiential activity: } \\
\text { - Select content suitable with lesson objectives, programs, kinds of students } \\
\text { - Design the topic, lessons or some activities in the topic, the lesson with the } \\
\text { activity } \\
\text { - Choose the conditions of facilities and materials suitable for students and } \\
\text { existing conditions } \\
\text { - Choose location, time, venue, organization style... }\end{array}$ & $\begin{array}{l}\text { - Provide information for teachers on conditions of } \\
\text { facilities, learning materials } \\
\text { - Provide information for teachers on the background of } \\
\text { the experience of individuals, personal interests related to } \\
\text { the content of the lesson... } \\
\text { - Provide personal information to teachers related to the } \\
\text { classification of students' learning style. }\end{array}$ \\
\hline 2 & $\begin{array}{l}\text { - Design the chain of activities to be consistent and clear with the objectives and } \\
\text { content of the lesson } \\
\text { - Each activity must clarify the organizational structure, tasks and products to be } \\
\text { achieved } \\
\text { - Each activity needs to create an experience environment for students to mobilize } \\
\text { and create their own experiences } \\
\text { - Prepare some options, situations to support students in difficulty } \\
\text { - Instruct students to observe, refine experience to have predictions, make } \\
\text { decisions on new concepts and assertion. } \\
\text { - Guide students to experiment, apply to new situations, new objects. }\end{array}$ & $\begin{array}{l}\text { - Prepare the conditions as required by the teacher: } \\
\text { - Prepare documents, learning materials } \\
\text { - Prepare facilities } \\
\text { - Read and study the materials as required } \\
\text { - Collect materials, statistics... as instructed }\end{array}$ \\
\hline 3 & $\begin{array}{l}\text { Get students to participate in the experience: } \\
\text { - Put students into the experiential environment, create students' needs for } \\
\text { learning and exploring things, keeping students' passion and interest during } \\
\text { activity } \\
\text { - Describe how the organization works (individual work, group ..., assign tasks to } \\
\text { groups and individuals) } \\
\text { - Giving tasks to individuals (teachers do this directly or through team leaders), } \\
\text { requirements on products and regulations to present the report. } \\
\text { - Get students to present their product report (individual or group representative) }\end{array}$ & $\begin{array}{l}\text { - Finish the assignment from teachers and the group } \\
\text { - Be willing to participate, to share, to cooperate; } \\
\text { affirming self value } \\
\text { - Receive HT mission and finish it step by step } \\
\text { - Initiate startup activity, ask for help to mobilize discrete } \\
\text { experiences } \\
\text { - Refining experience to make judgments, decisions and } \\
\text { concepts } \\
\text { - Experiment and make decisions. Continue the trajectory } \\
\text { cycle until the product target is achieved } \\
\text { - Present the product report. }\end{array}$ \\
\hline
\end{tabular}




\begin{tabular}{|c|l|l|}
\hline Steps & \multicolumn{1}{|c|}{ Teacher's activities } & \multicolumn{1}{c|}{ Students' activities } \\
\hline \multirow{4}{*}{4} & $\begin{array}{l}\text { Organize the evaluation for the activity: } \\
\text { - Guide on how to evaluate, set criteria; requirements of the product } \\
\text { - Guide on how to evaluate the process and the product } \\
\text { - Vote and reward if possible } \\
\text { - Recognize the value, success, creativity of the collective and the individual. }\end{array}$ & $\begin{array}{l}\text { - Study on how to evaluate, criteria, requirements of the } \\
\text { product } \\
\text { - Evaluate according to given instructions } \\
\text { - Join the vote and the praise. }\end{array}$ \\
\hline 5 & $\begin{array}{l}\text { Conclude and apply to new situations } \\
\text { - Share experiences } \\
\text { - Give conclusions of the core issues according to the objectives of the lesson } \\
\text { - Imagine pondering for contemplation, applying to new situations. }\end{array}$ & $\begin{array}{l}\text { - Share experiences with the teacher or among students } \\
\text { - Memorize the conclusions } \\
\text { - Ponder and contemplate } \\
\text { - Prepare a plan for new situations }\end{array}$ \\
\hline
\end{tabular}

\section{Conclusion}

The above steps are the core issues in the process of teaching mathematics to students in secondary schools through experiential activities, which is summarized from the experiences gained through the process of supervising and giving directions to the general education reform in Vietnam in the past few years in the combination with the experiences from other oversea and domestic authors. We have gone deeply into the techniques of selecting and building the content for the experiential activity; giving a name to the activity, getting ready for the conditions of facilities, time, location and organization style; techniques in designing the activity and practices of organizing and evaluating the experiential activity [3]. We believe that what we have mentioned above will be very useful for teachers in the process of implementing education reforms in order to meet the requirements of the new general education curriculum in Vietnam at the present time.

\section{References}

[1] Ministry of Education and Training (2017), General Education Program, Master Program, July 2017.
[2] Do Ngoc Thong (2014), Experiential activities - international experiences and problems of Vietnam, Workshop proceedings: TNST activities of high school students, Ministry of Education and Training in August 2014.

[3] Nguyen Huu Tuyen (2018), Designing experiential activity activities in teaching maths to lower secondary students congruent with the new general education curriculum in Vietnam, America Journal of Educational Research, Vol. 6, NO 5, 396-402.

[4] Nguyen Thi Lien, Nguyen Thi Hang, Duy Duy Hai, Dao Thi Ngoc Minh (2016), Creative learning activities in the school, Vietnam Education Publishing House.

[5] David A. Kolb (2015), Experiential Learning: Experience as a Source of Learning and Development, Englewood Cliffs, NJ: Prentice Hall.

[6] Ministry of Education and Training (2015), Training materials: Skills for building and organizing creative experiential activities in primary school, Publisher of Pedagogic University, Hanoi.

[7] Ministry of Education and Training (2015), Training materials for science and technology experiential learning activities and science and technology contest for high school students, August 2015, Hanoi.

[8] Bernd Meier, Nguyen Van Cuong (2014), Theory of Modern Teaching - Reasoning of Objectives, Contents and Methods of Teaching, Publisher of Pedagogical University.

[9] Chesimet, M. C.; Githua, B. N.; Ng'eno J. K. (2016), Effects of Experiential Learning Approach on Students' Mathematical Creativity among Secondary School Students of Kericho East Sub-County, Journal of Education and Practice, v7 n23 p51-57, Kenya. 